\title{
Laços entre família e serviços de Saúde Mental: a participação dos familiares no cuidado do sofrimento psíquico
}

Bárbara Souza Rodriguez Covelo(a)

Maria Inês Badaró-Moreira(b)

Covelo BSR, Badaró-Moreira MI. Links between family and mental health services: family members' participation in care for mental distress. Interface (Botucatu). 2015; 19(55):1133-44.

Family members' participation in care for mental distress is discussed through participant observation and interviews. It was possible to build up an analytical body of data on how the dimensions of care and distress are constituted within the family sphere. The data were treated through content analysis. Family members reported that they lacked time and space to take care of themselves, which caused discomfort because of the mental distress present in their lives. A territorial caregiving network is indicated as support for family members who play important roles within care provision. They have a need to talk about their day-to-day struggles, but healthcare services do not have strategies for attracting them towards participation, which gives rise to difficulty in making progress towards deinstitutionalization. Moments for listening to and comprehending family distress are presented as ways of welcoming and caring for family members.

Keywords: Mental Health. Family. Psychosocial attention. Networks.
Discute-se a participação dos familiares no cuidado do sofrimento psíquico, por meio de observação participante e entrevistas. Foi possível constituir um corpo analítico de como as dimensões do cuidado e do sofrimento se constituem no âmbito familiar. Os dados foram tratados mediante a análise de conteúdo. Os familiares relatam falta de tempo e espaços em que possam se cuidar, gerando desconforto frente à presença do sofrimento psíquico em suas vidas. Uma rede territorial de cuidados é apontada como um apoio aos familiares, considerados importantes atores para o plano de cuidados. Eles apresentam demandas de falar sobre seus sofreres cotidianos, no entanto os serviços de saúde não apresentam estratégias para atraílos a participar, o que dificulta avanços na desinstitucionalização. Momentos de escuta e de compreensão do sofrimento familiar são apresentados como formas de acolhimento e cuidado.

Palavras-chave: Saúde Mental. Família. Atenção psicossocial. Redes.

\footnotetext{
(a) Mestranda, Programa de Pós-Graduação Interdisciplinar em Ciências da Saúde, Departamento Políticas Públicas e Saúde Coletiva, Universidade Federal de São Paulo (Unifesp), campus Baixada Santista. R. Silva Jardim, 136, Vila Matias. Santos, SP, Brasil. 11015-020. bsrcovelo@gmail.com (b) Departamento Políticas Públicas e Saúde Coletiva, Unifesp, campus Baixada Santista. Santos, SP, Brasil. maria.ines@unifesp.br
} 


\section{Introdução}

Dada a importância da família para os planos de cuidados no âmbito da saúde mental, cada vez mais, formas de atuação conjunta e voltadas aos familiares são discutidas. A partir da Reforma Psiquiátrica, o cuidado próximo ao âmbito familiar é valorizado por ter um impacto positivo na reabilitação psicossocial, entendida como o processo de restituição do poder contratual para a ampliação da autonomia do usuário, segundo Kinoshita1.

Um sofrimento psíquico não se refere apenas ao membro que se desestabiliza, mas diz respeito a todos que compõem o universo familiar. A presença dele pode configurar um desgaste material, subjetivo, organizativo e social na família, porque o usuário de saúde mental pode se tornar dependente de seus familiares².

Quando o serviço se apresenta como parceiro da família, ela também contribui diretamente com a reabilitação psicossocial ${ }^{3}$. Por isso, esses equipamentos incluem os familiares no Projeto Terapêutico Singular (PTS) do usuário, também lhes ofertando um cuidado especial ${ }^{4}$.

O incentivo ao empoderamento de familiares e usuários é relevante para a construção de avanços na desinstitucionalização em saúde mental ${ }^{5}$. Para isso, eles precisam lidar com suas dificuldades cotidianas. Segundo Borba et al. ${ }^{6}$, ao se identificar a percepção da família com relação ao sofrimento psíquico, à pessoa e ao seu cuidado, pode-se concluir que lidar com família é lidar com sofrimento. Entretanto, os familiares não estão habituados a falar sobre a dimensão subjetiva, relacionada a sentimentos, preocupações e percepção da experiência de conviver com o sofrimento psíquico 7 .

Para esses familiares, essa dimensão pode ser algo novo, pois, antes, era vista como causa da doença, da qual deveriam se distanciar; mas, atualmente, a participação deles no cuidado é requisitada. Em diversos países, os familiares não recebem o apoio institucional necessário para que desempenhem o papel de cuidadores ${ }^{8}$. A falta de apoio fez com que, muitas vezes, o regresso da pessoa com sofrimento psíquico ao convívio familiar desencadeasse dificuldades na dinâmica da família, levando a reinternações.

Vale lembrar a importância de familiares e usuários para as transformações advindas da Reforma Psiquiátrica brasileira, a partir do II Congresso Nacional de Trabalhadores de Saúde Mental de Bauru, em 1987, quando passaram a participar, efetivamente, do movimento que antes era, predominantemente, de trabalhadores. Esta participação social no movimento da saúde mental contribuiu para tomadas de decisões e conquistas importantes na área, por exemplo, na dimensão jurídico-política9.

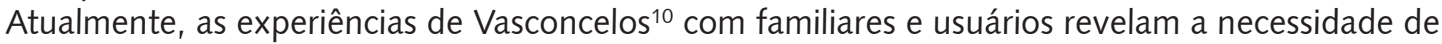
se trabalhar resgatando os preceitos e conquistas das mudanças na atenção em saúde mental e de se promover o empoderamento, como estratégias de fortalecimento da autonomia, do poder e da autoorganização. Para o autor, este exercício se apresenta como uma estratégia global de organização dos familiares para uma superação na ausência de apoio nos cuidados, ressoando positivamente na luta pela Reforma Psiquiátrica.

Neste sentido, confirma-se a necessidade da construção de uma rede ampliada, articulada de forma intersetorial, voltada à complexidade da vida humana na sua extensão para os diversos campos do existir, ou seja, uma rede que se expanda além da família e do serviço de atenção psicossocial.

Conforme a Portaria 3.088/2011 do Ministério da Saúde, que institui a Rede de Atenção Psicossocial (RAPS), a organização dos serviços em rede de atenção à saúde com base territorial, visando ações intersetoriais, é necessária para garantir a integralidade do cuidado. Este arranjo tem como finalidade a criação, ampliação e articulação de pontos de atenção às pessoas com sofrimento psíquico e com necessidades decorrentes do uso de crack e outras drogas no SUS ${ }^{11}$.

O Centro de Atenção Psicossocial (Caps) é definido como um ponto de atenção da RAPS, de acordo com a Portaria 3.088 ${ }^{12}$. Segundo Yasui ${ }^{13}$, o Caps está para além de um serviço, é uma forma de tessitura "de um cuidado que não se faz em apenas um lugar, mas é tecido em uma ampla rede de alianças" (p.115). Esta ideia de rede tecida em diversos pontos, com importante articulação entre os serviços, potencializa o arranjo para o necessário convívio, a manutenção do indivíduo com sofrimento psíquico intenso em sua família e comunidade. 
Dentro da perspectiva de atenção psicossocial, um dos objetivos do Caps é incentivar a participação familiar no serviço, por ser o vínculo mais forte do usuário com o mundo. Os familiares podem tanto estimular o usuário no seu PTS como podem participar ativamente das atividades do Caps e ajudar na integração social dele ${ }^{11,12}$.

Essa preocupação de inserção da família no cuidado reflete uma rede a ser constituída com diversos atores, em que o cuidar se constrói por meio do comprometimento e da implicação com o outro. Dessa forma, é necessário reconhecer o outro como sujeito, e não como objeto de intervenção ${ }^{13}$.

O cuidado em saúde mental sofreu diversas transformações, dentre elas, a valorização da família como ator importante para a atenção psicossocial. O apoio constante aos familiares é recomendável para conseguirem lidar com suas emoções quanto ao sofrimento psíquico, a fim de terem condições para executar seu cuidado ${ }^{14}$.

Nesse sentido, há necessidade de se voltar o olhar para os familiares, a fim de evidenciar a problemática familiar no cuidado e diversificar a rede de trocas afetivas. Tendo em vista o exposto, o objetivo deste trabalho é discutir a participação dos familiares no cuidado do sofrimento psíquico.

\section{Metodologia}

Trata-se de uma pesquisa de caráter qualitativo, cuja aproximação ao campo foi feita por meio de observação participante em um serviço de atenção psicossocial e em reuniões de um movimento social em Saúde Mental na cidade de Santos-SP.

A observação participante no serviço ocorreu por intermédio da inserção em atividades com usuários, familiares e profissionais. Primeiramente, os usuários foram informados sobre a proposta da pesquisa e convidados a participar. Além das entrevistas nos serviços, pedia-se que eles indicassem um familiar-cuidador, no intuito de deixá-los nomear quem reconhecessem como participantes do seu cuidado.

Dessa forma, o pedido de indicação do familiar foi elementar para preservar essa relação. Quando os familiares eram convidados a participar, eram questionados sobre o local da entrevista e optavam por realizá-la em suas casas, o que permitiu uma aproximação da pesquisa com a realidade dos usuários e familiares. Com a entrada em suas residências, uma relação delicada foi se estabelecendo entre pesquisador e pesquisado, em que as ações para a coleta de dados estavam permeadas pelo convite a adentrar no universo particular do cotidiano de cada família visitada. Nesse momento, ética e pesquisa qualitativa estavam indissociáveis, na medida em que a autonomia do pesquisador estava aliada à responsabilidade com os desejos do pesquisado ${ }^{15}$.

Os dados foram coletados por meio de entrevistas semiestruturadas com cinco usuários e sete familiares de um Caps da modalidade 3. Essa modalidade funciona durante 24 horas diariamente, incluindo fins de semanas e feriados, sendo responsável por ações como: internações; atendimentos individuais, domiciliares, grupais e familiares; oficinas terapêuticas; acolhimento noturno; entre outras $^{12}$.

As temáticas abordadas nas entrevistas foram: histórico, convívio e constituição familiar; relação com os serviços de atenção psicossocial; participação no cuidado da pessoa com sofrimento psíquico; e relação com a comunidade.

Os dados produzidos foram analisados na perspectiva da análise de conteúdo, a partir de Bardin ${ }^{16}$. Tal método abrange um conjunto de técnicas de análises das comunicações visando obter indicadores que permitam a inferência de conhecimentos relativos às condições de produção dessas mensagens. A modalidade da análise de conteúdo escolhida foi a temática, que busca descobrir núcleos de sentido que podem ter algum significado para o objetivo analítico.

Para esse tipo de análise, as entrevistas foram transcritas e lidas sucessivamente, assim como os diários de campo, com a finalidade de elaboração de núcleos de sentido e aproximação destes com a bibliografia e com a vivência do pesquisador.

A partir desse processo, os núcleos de sentido criados foram: 1) Família e serviço; 2) Redes; 3) Análise do sentido do sofrimento a partir dos familiares. 
Os familiares entrevistados serão referidos por F1, F2 etc. Os usuários de serviço de saúde mental entrevistados serão identificados como U1, U2 etc. Serão indicados idade e gênero de todos os entrevistados.

O presente estudo foi aprovado em 08/02/2012 pelo Núcleo de Bioética da Universidade Federal de São Paulo.

\section{Resultados e discussão}

\section{1) Família e serviço}

A aproximação com esses familiares de usuários da saúde mental foi um desafio nesta pesquisa, visto que somente um deles frequentava assiduamente o serviço.

Os familiares se queixavam da falta de tempo e do excesso de tarefas desempenhadas com o usuário de saúde mental no cotidiano, fazendo com que deixassem de fazer atividades voltadas ao lazer ou ao cuidado de si. De acordo com Stein et al. ${ }^{17}$, os pais de pessoas com sofrimento psíquico sentem uma grande perda de papéis sociais e de suas atividades rotineiras por causa dos cuidados com seus filhos.

Isso é preocupante, pois, como Idstad et al..$^{18}$ relatam, ter momentos de lazer e cuidado de si ajuda a proteger, significativamente, o desgaste do cuidador enquanto estiver passando por momentos de esgotamento frente às demandas.

"Com esse negócio de ficar com U1, a gente não tem direito de viajar. Não tem direito de fazer absolutamente nada". (F1, homem, 50 anos)

A maioria dos entrevistados relata que seus parentes e amigos se afastaram após o surgimento do sofrimento psíquico na família. Esse afastamento se torna prejudicial ao usuário, que se sente rejeitado e abandonado, e ao cuidador, que sente um desgaste maior por não ter ajuda. Há uma repetição na família do que acontece com a pessoa com sofrimento psíquico na comunidade, conforme Moreno ${ }^{19}$.

“Ele (pai) não liga nem para saber como a gente tá, nem como ela tá. Não quer saber, a única pessoa mesmo que tem, sou eu e as pessoas ainda falam assim: 'como você aguenta ficar com a sua irmã? Se eu fosse você levava na casa do seu pai e largava ela lá'". (F1, homem, 50 anos)

Para os familiares, a dificuldade de frequentar o serviço de saúde mental tem relação com a falta de tempo. Outra hipótese é de que a reduzida assiduidade nos serviços reforce o distanciamento deles por causa da história do papel da família na saúde mental, tal como o relato de Borba et al. ${ }^{6}$.

A ausência em ações de saúde mental faz com que os familiares não usufruam de espaços em que o sofrer cotidiano pode ser amparado e que possam se articular com demais familiares para conquistarem alguns direitos em relação ao cuidado de si e do usuário.

Nas entrevistas, os familiares demonstraram precisar falar sobre suas vivências e sofrimentos. Tal angústia poderia ser minimizada em encontros entre familiares dentro do Caps. Entretanto, a maioria não frequenta essa atividade, por opção ou por falta de oportunidade. Diante dos desafios da aproximação entre familiares e serviços, os usuários relatam a sensação de isolamento e a necessidade de articulação entre os serviços que tomem usuário e familiares como centralidade de suas ações e acolham o sofrimento inserido na dinâmica familiar. Além disso, eles reivindicam maior espaço para que seus familiares também encontrem apoio e orientação sobre o que se passa nos momentos mais delicados de sofrimento e crise $\mathrm{e}^{20}$.

Serviços de atenção psicossocial que oferecem cuidado ao familiar e uma coconstrução do cuidado se apresentam de forma diferente dos demais, porque a família tende a ter maior disponibilidade em participar ativamente do PTS. 
"Eles (profissionais do Caps) fizeram uma proposta de ele ficar internado e eu ficar junto o dia todo. Eu só vinha dormir em casa. [...] A psicóloga falou que seria uma forma diferente, que eu ia mostrar que eu tava junto com ele e não como eu sempre fiz, de largar ele em hospital e vim embora. [...] Acho que foi isso que funcionou". (F2, mulher, 75 anos)

A aproximação entre família e serviço se torna complexa, tanto pelas dificuldades dos familiares em atenderem ao que é requerido pela instituição no cuidado com a pessoa em sofrimento psíquico, quanto pelo fato de o serviço não os perceber como parte do cuidado, ao interagir com eles de forma apenas pontual.

Os usuários, constantemente, falavam de seus familiares e de suas histórias cotidianas, revelando quanto este ambiente é importante para eles. Essas falas demonstram como a situação familiar é algo que lhes afeta, em consequência: do cuidado recebido, das expectativas em torno de uma melhora clínica, além da percepção de que há algo de errado com seu parente, entre outros fatores que podem influenciar positiva ou negativamente em seu cuidado.

Em consonância com o que Camatta e Schneider ${ }^{21}$ trazem em seu estudo, os familiares tendem a ficar satisfeitos com o serviço pelo fato de o usuário estar estabilizado nos seus sintomas psíquicos, na diminuição do número de crises e reinternações psiquiátricas.

"Ela melhorou bem. O doutor curou com esse remédio que deu pra ela". (F1, homem, 50 anos)

Apesar de várias mudanças trazidas com a Reforma Psiquiátrica, tais aspectos mostram como o cuidado do sofrimento psíquico está permeado por uma visão médico-centrada, focada em seus aspectos sintomatológicos, em que sujeito se torna um objeto aos olhos da ciência ${ }^{22}$.

Nas entrevistas, os familiares dizem valorizar o Caps, sobretudo pelos cuidados oferecidos aos usuários, mas, também, porque, quando estes estão no Caps, os familiares descansam e se permitem fazer outras atividades.

"Dou graças a Deus de ter isso daqui (Caps), porque ele não pode ficar em casa direto, porque eu tenho ocupação, não dá". (F3, homem, 82 anos)

Neste relato, o Caps aparece como dispositivo de afastamento da pessoa com sofrimento psíquico de sua família, o que lhe confere um significado distorcido frente a sua tarefa em se tornar, cada dia mais, um espaço terapêutico capaz de "colocar em movimento trocas sociais bloqueadas" e reinscrever o sujeito no corpo social23.

A maioria dos familiares avalia o serviço com negatividade. Não gostam de frequentá-lo, dizendo não haver um acolhimento para eles, porque, em momentos de necessidade, não se ofereceu uma escuta ou houve inadequações em alguma atividade dirigida a esse público. Dessa maneira, tais situações geraram pouco envolvimento da família com o serviço, o que pode repercutir negativamente no cuidado ao usuário.

O contato dos familiares com esse dispositivo psicossocial acontece, sobretudo, quando acompanham consultas médicas, requisitam medicamentos ou são chamados pela equipe para conversar sobre o sujeito em sofrimento psíquico.

"[...] eu não vou para o Caps, só vou, assim, quando precisa trocar o remédio dela, alguma coisa. Ai eu vou lá, falo com o médico". (F4, mulher, 34 anos)

Na maioria dos casos, o envolvimento do familiar é remetido ao cuidado clínico. Não há relatos da participação familiar no PTS do usuário do Caps, que deve ser construído em conjunto com os sujeitos envolvidos (profissionais, familiares e usuários), tendo como referencial as histórias singulares de cada um, especialmente quando relacionadas ao sofrimento psíquico ${ }^{21}$. 
O familiar requer cuidado para cuidar do outro. De acordo com Borba et al. ${ }^{6}$, os familiares, antes de exercerem o papel de cuidadores, precisam de estratégias para lidar com as situações adversas e trabalhar com seus anseios. Ainda, a ausência de informação do familiar quanto às suas responsabilidades e formas de cuidado pode se tornar prejudicial tanto para si quanto para o usuário ${ }^{24}$.

Os grupos de família oferecem a possibilidade de os familiares elaborarem seus sofrimentos e pensarem juntos sobre estratégias singulares para lidarem com o sofrimento psíquico em suas vidas. Essa atividade, comum em serviços de saúde mental, é considerada instrumento poderoso para a autorreflexão, educação em saúde mental, e criação de vínculos entre serviço e família, sendo muito valorizada em diversas pesquisas ${ }^{19,25-28}$.

"Me sinto apoiada (no grupo de família), porque o pior que tem é não ter onde se socorrer, não ter um socorro quando você tem um filho envolvido nessas coisas. [...] Então, compartilhando é bem melhor". (F5, mulher, 59 anos)

Essa articulação entre equipamentos de saúde mental e família está ainda em desenvolvimento e apresenta fragilidades, como: falta de profissionais preparados para lidar com essa demanda, excesso de atendimentos para os trabalhadores, falta de recursos dos serviços de saúde mental, e falta de entendimento ou conhecimento, pelos familiares, das novas propostas da saúde mental?

A inserção da família não foi efetivada completamente nos serviços substitutivos, e só se dá importância a esse aspecto quando se foca em ações para o usuário. Não há um reconhecimento dela como passível de sofrimento, mas como um potencial manejador de cuidado clínico, como afirma Bieleman et al. ${ }^{27}$. Os familiares precisam ser vistos como sujeitos da ação e parte da atenção dos profissionais para se desenvolverem como suporte de cuidado.

De acordo com Duarte e Kantorski ${ }^{26}$, a melhor estratégia para aproximar a família dos serviços é o reconhecimento da importância de seu papel para o cuidado do usuário, por meio de falas realizadas pelos profissionais, que também devem lhe oferecer apoio e escuta, além de convidá-la para atividades na rede de saúde mental. Sendo assim, percebe-se que as melhores opções de cuidado aos familiares envolvem o uso de tecnologias leves, conceituadas por Merhy ${ }^{29}$.

\section{2) Redes}

A Reforma Psiquiátrica brasileira advém da articulação de atores sociais que exigiram do Estado a concretização de seus direitos. Alianças e trocas foram realizadas como uma rede para avanços desse movimento social. Consequentemente, essa lógica é difundida, nos preceitos do Caps, como um serviço potente para ativação de recursos como: "diferentes segmentos sociais, diversos serviços, distintos atores e cuidadores" (p. 115). Trata-se da utilização e da criação de espaços no território por meio das relações, que possibilitam a constante transformação do lugar existencial do sujeito ${ }^{13}$.

Dois familiares ativos no campo da saúde mental expuseram como a participação dos familiares é escassa em ações dentro do serviço e em outros espaços de articulação. Ambos iniciaram o contato com essa área quando seus filhos começaram a frequentar um dos primeiros Caps implementados no Brasil, assim acompanhando de perto a história da Reforma Psiquiátrica brasileira.

A forma de agir desses familiares, envolvidos com políticas de saúde mental, não representa a maneira como os demais estão presentes/ausentes no cenário da reforma psiquiátrica hoje. No campo afetivo e político, eles encontraram estratégias eficientes para o cuidado de si e de seus filhos.

Assim como outros familiares entrevistados, eles privilegiam, em seus cuidados, dar tarefas aos usuários priorizando sua autonomia. Há uma postura diferente da lógica manicomial em relação à pessoa com sofrimento psíquico, na medida em que visa a um novo posicionamento do sujeito acerca de sua condição de passividade para uma atitude de "autoadministração", reconhecendo suas possibilidades de modificar o contexto vivido ${ }^{30}$. 
"Meu quarto é bem arrumado. Eu limpo todo dia. Eu lavo minhas roupas. Ajudo minha sobrinha, minha irmã. Eu vou na padaria, eu vou no açougue. Então, eu sou louca?". (U1, mulher, 48 anos)

A compreensão destes familiares sobre o sofrimento psíquico, o funcionamento da rede de saúde mental e as propostas da reforma psiquiátrica mudou seus olhares em relação ao impacto da loucura em suas vidas.

A desinformação sobre o sofrimento psíquico causa desentendimentos na família, por ela não entender o comportamento do usuário de saúde mental e cobrar que ele tenha funções para as quais não se sente apto. Logo, é uma situação que causa sofrimento na família como um todo.

\footnotetext{
"Até acharam que ele ia trabalhar, mas diz que ele falou que falaram pra ele não trabalhar. [...] Eu não acredito que alguém falou isso que ele não pode trabalhar. [...] Ai será que ele escuta, certeza? [...] Eu acho que é coisa do diabo. E agora? Eu até pensei que o U2 tinha alguma coisa, mas nunca levei ele em lugar nenhum não, mas eu já me conformei". (F6, mulher, 43 anos)
}

Foi a partir da troca de experiências, da identificação com o outro e da articulação de ideias em um grupo de família que os familiares ativos na Reforma Psiquiátrica aumentaram a percepção sobre as potências do usuário e se sentiram importantes no processo de reabilitação psicossocial. Dessa forma, buscaram conhecimento para aprimorar seus papéis no cuidado e na luta antimanicomial.

Como a maioria dos familiares frequenta pouco o âmbito da saúde mental, não conhece as propostas de desinstitucionalização, dentre elas a corresponsabilização entre profissionais e familiares, que evitaria o desgaste de ambos os lados.

A parceria entre serviço e a família é uma estratégia de mobilização e comprometimento para lidar com a loucura no território, proporcionando potencialidades de trocas entre serviço, usuário e sua rede social ${ }^{19,28}$. Atualmente, a implementação destas ações está bastante limitada. Ademais, o trabalho da desinstitucionalização, conforme Rotelli ${ }^{23}$, é reconstruir as pessoas como atores sociais. Logo, seria importante que os serviços se integrassem a redes de cuidados, nas quais os familiares pudessem ser ativos e envolvidos com a implantação de novos rumos da assistência.

Além dos serviços, é importante lembrar que existem outros espaços que podem vir a potencializar ou notar o papel da família como parte do cuidado, como: eventos de saúde mental, movimentos sociais e interação com a família em seu território.

Um espaço excelente para enxergar o papel da família e dar voz e escuta aos familiares é sua residência. Durante esta pesquisa, as entrevistas foram realizadas nos lares dos familiares e usuários, o que possibilitou observar como estes se relacionam com outros personagens importantes de sua história.

No acompanhamento domiciliar de pessoas com sofrimento psíquico, a abordagem familiar é uma forma de envolver esses membros nos projetos terapêuticos, o que demanda escutá-los para compreender suas dificuldades e conhecer suas redes sociais no território.

Eventos de saúde mental e movimentos sociais são momentos para além do serviço que possibilitam que usuários e familiares (re)ativem vínculos, o que vai ao encontro do projeto terapêutico do usuário e potencializa o papel da família como importante no cuidado.

\section{3) Análise do sentido do sofrimento a partir dos familiares}

O surgimento do sofrimento psíquico numa família transforma suas relações. Em alguns dos familiares a mudança será maior, em razão da proximidade com o usuário da saúde mental. Isso acontece, pois a família é uma extensão do ente com sofrimento psíquico, segundo Casse ${ }^{31}$, por isso, além de submeter-se a mudanças concretas no cotidiano em razão do cuidado, tende a sofrer junto com ele.

De acordo com Cassel ${ }^{31}$, o sofrimento, geralmente, é associado à dor, mas nota-se que é um sentimento com diversas dimensões no indivíduo, como: cultural, familiar, política, temporal, 
entre outras. Essencialmente, as perdas e privações relacionadas a essas dimensões podem gerar o sofrimento. Com base nessas dimensões, o sofrimento é entendido como uma "vivência da ameaça da ruptura da unidade/identidade da pessoa"14 (p. 32).

Alguns familiares descreveram ter outros planos para seus filhos, como exercerem uma profissão, o que foi impossibilitado pela doença. À vista disso, é inevitável notar as expectativas dos pais para os filhos continuarem os projetos familiares, mas, infelizmente, o aparecimento do sofrimento psíquico grave impede tal realização e gera sentimentos de frustração e de culpabilização aos familiares ${ }^{4}$.

"Pra mim, eu não gostaria que meu filho tivesse se tratando, entendeu? [...]. Eu tinha outros propósitos para ele, para esses problemas de saúde mental. Ter um homem que trabalhasse". (F6, mulher, 43 anos)

Caso os familiares-cuidadores venham a falecer, eles se preocupam com o que acontecerá com seus entes com sofrimento psíquico. Isso mostra como as projeções são fontes de sofrimento, visto que todos colocam expectativas, desejos e crenças no futuro, e a doença pode causar um temor de perder esta vida futura ${ }^{14,31}$.

“É, né? Aí você vai fazer o que, no caso se eu for primeiro que ele? Ah minha preocupação é essa. Ele vai ficar apoiado pelos irmãos, mas irmão não é mãe, viu?". (F3, mulher, 59 anos)

Percebe-se a culpabilização dos pais pela doença dos filhos na busca de possíveis erros cometidos no passado, para encontrar sentidos e explicações que possam diminuir seu sofrimento ${ }^{32}$.

“É assim, quando uma pessoa tá grávida, ela quer o melhor [...]. 'Quero que meu filho nasça saudável'. Mas eu tinha um monte de pensamento negativo". (F5, mulher, 59 anos)

Dentre os familiares entrevistados, uma mãe relata ver relação da doença do filho com suas atitudes durante a gestação, indicando uma autoculpabilização, movida por crenças e conflitos morais. De acordo com Cassel ${ }^{31}$, o enfrentamento da doença é influenciado pelo passado e presente. No presente, em decorrência de condições clínicas, pessoas com sofrimento psíquico podem abandonar ou ter dificuldade de realizar algumas atividades que, antes, Ihes eram cotidianas, o que, por parte do cuidador, pode ser visto como uma descaracterização do sujeito.

Há a perda de um papel social e político, pela perda da função da representatividade e da forma de ser visto pelo demais, e uma transformação do papel familiar, porque, muitas vezes, um pai e um irmão que adoecem passam a ter o papel de filho para quem cuida, devido aos tipos de cuidados, tal como nesta fala do irmão de uma usuária.

"U2 é minha filha, né? Minha filha. Eu trato ela como filha". (F1, homem, 50 anos)

Os aspectos culturais e morais, que envolvem valores e crenças, também são muito influentes no sofrimento ${ }^{31}$. Crenças são capazes de atribuir sentido às vivências, podendo mostrar um lado de culpa, que faz o cuidador sofrer. Os conflitos morais como fonte de sofrimento eram presentes na vida destes familiares. Muitas vezes, os familiares desejaram a internação ou a morte de seus entes com sofrimento psíquico, mas referiram tais desejos como inapropriados.

Uma transformação cultural e política na vida dessas famílias foi o redirecionamento da assistência em Saúde Mental. No Brasil, a partir do século XIX, a história da psiquiatria é também de um processo de asilamento e medicalização social ${ }^{33}$. A partir do final da década de 1970, quando a ideia do cuidado em liberdade é iniciada como uma perspectiva prática, evidenciou-se o desafio de conviver com a loucura em suas casas e comunidades. Desde então, uma das importantes ações dos serviços de atenção psicossocial também deve ser o apoio aos familiares em como lidar com o sofrimento psíquico.

A Reforma Psiquiátrica brasileira se configurou a partir das quatro dimensões, referidas por Yasui ${ }^{13}$ : sociocultural, política, epistemológica e técnico-assistencial. Constantemente imbricadas e em contínua 
transformação, possibilitam o surgimento de novas crenças, valores, práticas e conhecimentos de como lidar com o sofrimento psíquico, com os quais os familiares passaram a entrar em contato. Para alguns, o conflito entre internar e cuidar é ainda muito constante, porque, mesmo que exista um novo aspecto em relação ao cuidado com a loucura, estamos diante de uma transição, em que algumas redes de cuidado possuem a internação psiquiátrica como posição central do cuidado.

A religião envolve cultura, moral, valores e crenças, e foi muito citada pelos familiares como uma forma de aliviarem seu sofrimento frente aos conflitos cotidianos. A valorização da fé e da esperança confere às pessoas uma forma de se restabelecerem plenamente depois de dificuldades, em decorrência de as pregações servirem de amparo para persistirem nessa caminhada junto ao sofrimento psíquico.

"Não tá me complicando tanto porque me pego com Deus. Entendeu? Ele que me dá força. Se não fosse Deus, eu nem taria aguentando tudo isso". (F4, mulher, 34 anos)

Essa aproximação dos familiares com a religião indica que a recuperação do sofrimento envolve apoio dos outros ${ }^{31}$. Stein et al. ${ }^{17}$ refere que os familiares tendem a ter mais consideração por quem lhes oferece apoio emocional. Consequentemente, seria importante que os serviços substitutivos de saúde mental buscassem dar atenção aos laços constituídos com os familiares e ressignificá-los, se necessário. Assim, como compreender quais pessoas estão inseridas no círculo familiar dos usuários.

A partir dos trabalhos basaglianos, a atenção psicossocial pode ser entendida como cuidar sem a busca da cura, uma vez que o foco são as relações e a complexidade da vida humana. Não se persegue a linearidade (problema-cura), e sim um mundo de uma pessoa que pode ser descoberto; e, ao se desvendar esse mundo, é possível criar um processo que seja de fato terapêutico. "O problema não é a cura, mas a produção de vida, de sentido, de sociabilidade, a utilização das formas (dos espaços coletivos) de convivências dispersas"23 (p. 30).

Ao serem consideradas, as diversas dimensões do sujeito promovem intervenções que reduzem o sofrimento e estimulam a retomada de vida ${ }^{14}$. Dessa maneira, ao trabalhar com a perspectiva da desinstitucionalização, o trabalho terapêutico é voltado para a reconstituição de pessoas, como sujeitos de suas histórias. E, neste modo de trabalhar, descobre-se que cuidar significa ocupar-se de alguém e possibilitar a transformação dos modos de viver e sentir o sofrimento, ao mesmo tempo em que haja mudança concreta e cotidiana de sua vida. Assim, o que se busca para usuários e familiares é uma existência mais rica em recursos, possibilidades e experiências. E, também, uma existência de mudanças contínuas, feitas de encontros diversos que vão ampliando suas trocas sociais e reduzindo o peso do sofrimento.

\section{Considerações finais}

Pode-se concluir como a participação da família no cuidado de pessoas com sofrimento psíquico é fundamental na atenção psicossocial. Contudo, a maioria dos familiares desconhece a importância de sua participação e como pode ativar laços com dispositivos sociais apoiadores no cuidado da pessoa com sofrimento psíquico. Em razão disso, fica evidente como o envolvimento desses familiares com a rede de saúde mental é limitado.

O cuidado tem como potencialidade a expansão de relações para transformar modos de viver. A família é um meio de constante mudança de ligações afetivas e sociais, com o qual o campo da Saúde Mental tem o desafio da aproximação. Tal contato se mostra importante para acolher as complexas dimensões do sofrimento desses familiares, por meio: da escuta, de atividades grupais e do entendimento de sua dinâmica vivencial.

O encontro da família com o serviço traz a possibilidade de criação de espaços onde se podem tecer laços rompedores de linearidades e reducionismos da vida. Os avanços na política de saúde mental dependem desta (re)ativação dos encontros permeados pela implicação com o sujeito e a perspectiva da desinstitucionalização. 


\section{Colaboradores}

A autora Bárbara Souza Rodriguez Covelo delineou o artigo, no qual apresenta dados derivados das pesquisas, experiências práticas e monografia orientadas pela Profa. ${ }^{\text {. }} r^{a}$. Maria Inês Badaró Moreira. Ambas as autoras participaram da discussão sobre estrutura e redação do artigo. A orientadora efetuou revisão crítica e fez sugestão à redação do manuscrito.

\section{Referências}

1. Kinoshita RT. Contratualidade e reabilitação psicossocial. In: Campos FCB, Henriques CMP, organizadores. Contra maré à beira mar: a experiência do SUS em Santos. 2a ed. São Paulo: Hucitec; 1997. p. 55-9.

2. Melman J. Família e doença mental: repensando a relação entre profissionais de saúde e familiares. 2a ed. São Paulo: Escrituras; 2002.

3. Moreno $\mathrm{V}$, Alencastre $\mathrm{MB}$. A trajetória da família do portador de sofrimento psíquico. Rev Esc Enferm USP [Internet]. 2003 [acesso 2014 Mar 20]; 37(2):43-50. Disponível em: http://www.scielo.br/scielo.php?script=sci_arttext\&pid=S008062342003000200006\&lng=en. http://dx.doi.org/10.1590/S0080-62342003000200006

4. Silva G, Santos MA. Álbum de família e esquizofrenia: convivência em retrato. Psicol Estud [Internet]. 2009 [acesso 2014 Mar 15]; 4(1):83-91. Disponível em: <http://www. scielo.br/scielo.php?script=sci_arttext\&pid $=\$ 1413-73722009000100011 \& \operatorname{lng}=\mathrm{en} \& \mathrm{nrm}$ =iso $>$. http://dx.doi.org/10.1590/S1413-73722009000100011

5. Dimenstein M, Sales AL, Galvão E, Severo AK. Estratégia da Atenção Psicossocial e participação da família no cuidado em saúde mental. Physis [Internet]. 2010 [acesso 2014 Fev 28]; 20(4):1209-26. Disponível em: http://www.scielo.br/scielo.php?script=sci arttext\&pid=S0103-73312010000400008\&lng=en. http://dx.doi.org/10.1590/S010373312010000400008

6. Borba LO, Paes MR, Guimarães AN, Labronici LM, Maftum MA. A família e o portador de transtorno mental: dinâmica e sua relação familiar. Rev Esc Enferm USP [Internet]. 2011 [acesso 2013 Nov 5]; 45(2):442-9. Disponível em: http://www.scielo.br/scielo. php?script=sci_arttext\&pid=S0080-62342011000200020\&lng=en. http://dx.doi. org/10.1590/S0080-62342011000200020

7. Cardoso L, Galera SAF, Vieira MV. O cuidador e a sobrecarga do cuidado à saúde de pacientes egressos de internação psiquiátrica. Acta Paul Enferm [Internet]. 2012 [acesso 2013 Maio 14]; 25(4):517-23. Disponível em: http://www.scielo.br/scielo. php?script=sci_arttext\&pid=S0103-21002012000400006\&lng=en. http://dx.doi. org/10.1590/S0103-21002012000400006

8. Van de Bovenkamp HM, Trappenburg MJ. The relationship between mental health workers and family members. Pat Educ Couns. 2010; 80(1):120-5.

9. Amarante P. Saúde Mental e Atenção Psicossocial. 3a ed. Rio de Janeiro: Editora Fiocruz; 2011.

10. Vasconcelos EM, organizador. Abordagens psicossociais: Reforma Psiquiátrica e Saúde Mental na ótica da cultura e das lutas populares. São Paulo: Hucitec; 2008. v. 2.

11. Portaria GM 3088, de 23 de dezembro de 2011. Institui a Rede de Atenção Psicossocial para pessoas com sofrimento ou transtorno mental e com necessidades decorrentes do uso de crack, álcool e outras drogas, no âmbito do Sistema Único de saúde (SUS). Diário Oficial da União. 23 Dez 2011.

12. Ministério da Saúde. Secretaria de Atenção à Saúde. Departamento de Ações Programáticas e Estratégicas. Saúde Mental no SUS: os Centros de Atenção Psicossocial. Brasília (DF): SAS; 2004. 
13. Yasui S. Rupturas e encontros: desafios da Reforma Psiquiátrica brasileira. Rio de Janeiro: Fiocruz; 2010.

14. Ministério da Saúde. Secretaria de Atenção à Saúde. Departamento de Atenção Básica. Saúde mental/Ministério da Saúde, Secretaria de Atenção à Saúde, Departamento de Atenção Básica, Departamento de Ações Programáticas Estratégicas. Brasília (DF): SAS; 2013.

15. Silva CRC, Mendes R, Nakamura E. A dimensão da ética na pesquisa em saúde com ênfase na abordagem qualitativa. Saude Soc [Internet]. 2012 [acesso 2014 Nov 12]; 21(1):33-41. Disponível em: <http://www.scielo.br/scielo.php?script=sci_ arttext\&pid=S0104-12902012000100005\&lng =en\&nrm=iso > http://dx.doi. org/10.1590/S0104-12902012000100005

16. Bardin L. Análise de conteúdo. Brasil: Editora 70; 1977.

17. Stein $\mathrm{CH}$, Aguirre R, Hunt MG. Social networks and personal loss among young adults with mental illness and their parents: a family perspective. Psychiatr Rehabil J. 2013; 36(1):15-21.

18. Idstad $M$, Ask $H$, Tambs K. Mental disorder and caregiver burden in spouses: the nord-trondelag health study. BMC Public Health [Internet]. 2010 [acesso $2013 \mathrm{Abr}$ 31]; 10(516): [cerca de 7p]. Disponível em: http://www.biomedcentral.com/14712458/10/516 > http:// dx.doi.org/10.1186/1471-2458-10-516

19. Moreno V. Familiares de portadores de transtorno mental: vivenciando o cuidado em um centro de atenção psicossocial. Rev Esc Enferm USP [Internet]. 2009 [acesso 2013 Out 7]; 43(3):566-72. Disponível em: http://www.scielo.br/scielo.php?script=sci arttext\&pid=S0080-62342009000300010\&lng =en. http://dx.doi.org/10.1590/S008062342009000300010

20. Badaró-Moreira MI, Andrade AN. Ouvindo Loucos: construindo possibilidades de viver com autonomia. Psic Saude Doença. 2003; 4(2):249-66.

21. Camatta MW, Schneider JF. A visão da família sobre o trabalho de profissionais de saúde mental de um centro de atenção psicossocial. Esc Anna Nery [Internet]. 2009 [acesso 2013 Mar 16]; 13(3):477-84. Disponível em: http://www.scielo.br/scielo. php?script=sci_arttext\&pid=S1414-81452009000300004\&lng=en. http://dx.doi. org/10.1590/S1414-81452009000300004

22. Basaglia F. Um problema da psiquiatria institucional - a exclusão como categoria sociopsiquiátrica. In: Amarante $\mathrm{P}$, organizador. Escritos selecionados em saúde mental e reforma psiquiátrica. Rio de Janeiro: Garamond; 2005. p. 35-59.

23. Rotelli F. A instituição inventada. In: Nicácio F, organizador. Desinstitucionalização. São Paulo: Hucitec; 1990. p. 89-99.

24. Parker R, Leggatt $M$, Crowe J. Public interest and private concern: the role of family carers for people suffering mental illness in the twenty first century. Australas Psychiatr. 2010; 18(2):163-6.

25. Santin G, Klafke TE. A família e o cuidado em saúde mental. Barbarói [Internet]. 2011 [acesso 2013 Mar 14]; (34):146-60. Disponível em: http:// online.unisc.br/seer/index. php/barbaroi/article/view/1643/1567

26. Duarte MLC, Kantorski LP. Avaliação da atenção prestada aos familiares em um centro de atenção psicossocial. Rev Bras Enferm [Internet]. 2011 [acesso 2013 Mai 25]; 64(1):4752. Disponível em: http://www.scielo.br/scielo.php?script=sci_arttext\&pid=S003471672011000100007\&lng=en. http://dx.doi.org/10.1590/\$0034-71672011000100007 
27. Bielemann VLM, Kantorski LP, Borges LR, Chiavagatti FG, Willrich Janaina JQ, Souza AS, et al. A inserção da família nos centros de atenção psicossocial sob a ótica de seus atores sociais. Texto Contexto Enferm [Internet]. 2009 [acesso 2014 Fev 18]; 18(1):131-9. Disponível: http://www.scielo.br/scielo.php?script=sci_arttext\&pid=S010407072009000100016\&lng=en. http://dx.doi.org/10.1590/S0104-07072009000100016

28. Schrank G, Olschowsky A. O Centro de Atenção Psicossocial e as estratégias para inserção da família. Rev Esc Enferm USP [Internet]. 2008 [acesso 2014 Mai 20]; 42(1):127-34. Disponível: http://www.scielo.br/scielo.php?script=sci arttext\&pid=S0080-62342008000100017\&lng=en. http://dx.doi.org/10.1590/S008062342008000100017

29. Merhy EE. Em busca de ferramentas analisadoras das tecnologias em saúde: a informação e o dia a dia de um serviço, interrogando e gerindo trabalho em saúde. In: Merhy $\mathrm{EE}$, Onocko R, organizadores. Agir em saúde: um desafio para o público. São Paulo: Hucitec; 2006. p. 13-150.

30. Aires M, Roos CM, Gonçalves AVF, Schneider JF, Olschowsky A. Ações em saúde mental às famílias nos diferentes contextos de trabalho: revisão integrativa. Rev Gaucha Enferm [Internet]. 2010 [acesso 2014 Mar 6]; 31(3):567-74. Disponível: http://www. scielo.br/scielo.php?script =sci_arttext\&pid=S1983-14472010000300023\&lng =en. http://dx.doi.org/10.1590/S19̄83-14472010000300023

31. Cassel E. The nature of suffering. In: Cassel $E$, organizador. The nature of suffering and the goals of medicine. New York: Oxford University Press; 1991. p. 30-47.

32. Navarini $V$, Hirdes A. A família do portador de transtorno mental: identificando recursos adaptativos. Texto Contexto Enferm [Internet]. 2008 [acesso $2013 \mathrm{Abr}$ 30]; 17(4):680-8. Disponível em: http://www.scielo.br/scielo.php?script=sci arttext\&pid=S0104-07072008000400008\&lng=en. http://dx.doi.org/10.1590/S010407072008000400008

33. Amarante P. Asilos, alienados e alienistas. In: Amarante P, organizador. Psiquiatria social e reforma psiquiátrica. Rio de Janeiro: Fiocruz; 1994. p. 73-81.

Covelo BSR, Badaró-Moreira MI. Los lazos entre la familia y los servicios de Salud Mental: la participación de los familiares en el cuidado del sufrimiento psíquico. Interface (Botucatu). 2015; 19(55):1133-44.

Se discute la participación de los familiares en el cuidado del sufrimiento psíquico por medio de observación participativa y de entrevistas. Fue posible constituir un cuerpo analítico de como las dimensiones del cuidado y del sufrimiento se constituyen en el ámbito familiar. Los datos se trataron mediante el análisis de contenido. Los familiares relatan falta de tiempo y espacios en los que puedan cuidarse, generando incomodidad ante la presencia del sufrimiento psíquico en sus vidas. Se señala una red territorial de cuidados como un apoyo a los familiares, considerados importantes actores para el plan de cuidados. Ellos presenta demandas de hablar sobre sus sufrimientos coitadnos, sin embargo los servicios de salud no presentan estrategias para atraer su participación lo que dificulta los avances en la desinstitucionalización. Los momentos de escucha y de comprensión del sufrimiento familiar se presentan como formas de acogida y cuidado.

Palabras clave: Salud mental. Familia. Atención psicosocial. Redes. 